\title{
Epidemiological investigation into the introduction and factors for spread of Peste des Petits Ruminants, southern Tanzania
}

\begin{abstract}
Authors:
Epaphras A. Muse

Esron D. Karimuribo ${ }^{2}$ George C. Gitao ${ }^{3}$

Gerald Misinzo Lesakit S.B. Mellau²

Peter L.M. Msoffe ${ }^{2}$

Emmanuel S. Swai ${ }^{4}$

Mbyuzi O. Albano ${ }^{4}$

Affiliations:

${ }^{1}$ Department of Veterinary Microbiology and

Parasitology, Sokoine University of Agriculture,

Tanzania

${ }^{2}$ Department of Veterinary Medicine and Public Health Sokoine University of Agriculture, Tanzania

${ }^{3}$ Department of Veterinary pathology, Microbiology and Pathology, University of Nairobi, Kenya
\end{abstract}

${ }^{4}$ Veterinary Investigation Centre Arusha, Tanzania

\section{Correspondence to:}

Epaphras Muse

Email:

epaphrasa@gmail.com

Postal address:

PO Box 3019, Chuo Kikuu,

Morogoro, Tanzania

How to cite this proceeding: Muse, E.A., Karimuribo, E.D., Gitao, G.C., Misinzo, G., Mellau, L.S.B., Msoffe, P.L.M. et al., 2012, 'Epidemiological investigation into the introduction and factors for spread of Peste des Petits Ruminants, southern Tanzania', Onderstepoort Journal of Veterinary Research 79(2), Art. \#457, 6 pages. http://dx.doi. org/10.4102/ojvr.v79i2.457

\section{Note:}

Proceedings of the Conference of the Southern African Centre for Infectious Disease Surveillance 'One Health' held at the National Institute for Communicable Diseases, Johannesburg, July 2011.
A study was carried out to confirm and identify sources and elucidate factors associated with the introduction of Peste des Petits Ruminants (PPR) in southern Tanzania. This study was conducted in Tandahimba and Newala districts of Mtwara region following suspected outbreak of PPR in the area. Qualitative data were collected using semi-structured questionnaires and in-depth interviews of key informants who included goat and sheep owners with suspected cases of PPR and animal health service providers as well as local administrative authority. Additionally, 216 serum samples and 28 swabs were collected for serological and virological laboratory disease confirmation. The results show that PPR was first introduced in Likuna village of Newala district in February 2009 through newly purchased goats from the Pugu livestock market located about $700 \mathrm{~km}$ in the outskirts of Dar es Salaam city. Factors which contributed to spread of PPR included communal grazing and the cheap prices of sick animals bought by livestock keepers for slaughtering in other villages. Laboratory findings confirmed presence of PPR in the area by RT-PCR and serological analysis revealed that seroprevalence was $31 \%$. These findings have confirmed, for the first time, introduction of PPR in southern Tanzania. The presence of PPR poses high risk of southward spread of the disease to other southern African countries in the SADC region thus calling for concerted and collaborative efforts in prevention and control of the disease to avoid losses. Further elaborate studies on the spread, prevalence and risk factors associated with the disease should urgently be investigated.

\section{Introduction}

Peste des Petits ruminants is an acute, highly contagious infectious disease of small domestic ruminants and small wild ruminants, such as antelopes, impala and gazelles (Abu Elzein et al. 2004; Nussieba et al. 2009). The disease is caused by Peste des Petits Ruminants (PPR) virus (PPRv). PPRv belongs to a Morbillivirus genus of Paramixyoviridae family. PPRv is a single serotype that is differentiated into four (I-IV) lineages (Forsyth \& Barrett 1995; Couacy-Hymann et al. 2002). The geographical distribution of PPR lineages varies as lineage I and II have been commonly reported in West Africa (Ashley et al. 2010), lineage III has been reported eastern Africa except for Sudan which has been found to harbour lineage IV in addition to lineage III (Khalafalla et al. 2010). On the other hand, lineage IV has been reported in Central and North Africa, Asia and China (Ozkul et al. 2002; Wang et al. 2009; Awa et al. 2000; Ayari-Fakhfakh et al. 2010; Balamurugan et al. 2010; Khalafalla et al. 2010).

The disease is transmitted by direct contact involving secretions or excretions from infected animals to healthy animals in close proximity. Clinically, PPR is characterised by sudden onset of depression, fever, lacrimation, sores in the mouth, dyspnoea and coughing, foul smelling diarrhoea and death. Post-mortem findings, normally restricted to the alimentary tract, consist of extensive erosive stomatitis and heamorrhagic gastro-enteritis, and often include streaks of congestion along the folds of the mucosa resulting in the characteristic 'zebra-striped' appearance (Chauhan et al. 2009). Secondary bronchopneumonia is common.

The disease is characterised by high morbidity and mortality $(50 \%-80 \%)$ in naive sheep and goats populations, impacting negatively on the livelihoods, food security and socio-economic activities of livestock keepers in affected areas. The disease also impacts negatively on the local and international livestock trade markets. In Tanzania the disease limits the efforts of farmers and government in attaining the millennium development goal for eradicating extreme poverty and hunger.

In Tanzania, PPR was first confirmed in 2008 in the northern areas (Kivaria et al. 2009; Swai et al. 2009), where it was confined until recently when it was suspected to have been introduced Copyright: (C) 2012. The Authors. Licensee: AOSIS OpenJournals. This work is licensed under the Creative Commons Attribution License. 
in southern areas in 2010 (FAO 2010). The presence of PPR in southern Tanzania would pose a high risk for spread to the whole of the Southern African Development Community (SADC) threatening to devastate the livelihoods and food security of millions of small herders and agro-pastoralists (FAO 2010). Until the current study was designed, no official confirmation of PPR in southern parts of the country had been carried out. The objectives of this study were:

- to confirm the presence of PPR in goats and sheep in Newala and Tandahimba districts, Mtwara region

- to identify sources and factors that contributed to the introduction and spread of the PPR in southern Tanzania

- to describe the epidemiological factors and losses in the affected villages.

The hypotheses were to confirm if suspected cases seen in goats and sheep in southern Tanzania were caused by PPRv and to find out which factors facilitate the spread of the disease in this zone.

\section{Material and methods Study area}

The study was carried out in eight selected villages in two districts of Mtwara region, Newala and Tandahimba districts, in southern Tanzania between March and May 2011 (Figure 1). The estimated census for humans, goats and sheep in these districts are shown in Table 1. The study area was purposively targeted following reports of suspected PPR outbreak that decimated small ruminants in the districts. This area borders Mueda district of the Cabo Delgado province of Mozambique with a small ruminant population that is naive to PPR. The study area lies between $2^{\circ} 11^{\prime}$ and $6^{\circ} 14^{\prime} \mathrm{S}$, and $35^{\circ}$ $11^{\prime}$ and $38^{\circ} 26^{\prime} \mathrm{E}$ at an elevation of $100 \mathrm{~m}-800 \mathrm{~m}$ above sea level. The rainy season starts in November and/or December to April and/or May with an average annual precipitation of $893 \mathrm{~mm}-1001 \mathrm{~mm}$. The mean monthly temperature varies from $23^{\circ} \mathrm{C}$ to $27^{\circ} \mathrm{C}$ and relative humidity varies from $79 \%$ to $87 \%$.

\section{Study design and data collection}

The current study employed a cross-sectional study design where selected villages were visited once between March 2011 and May 2011. Purposive sampling of animals was carried out in villages with suspected PPR cases based on opinion from local veterinary officials and leaders. Upon identification of household with suspected cases, the researcher (EAM) conducted detailed interviews with owners of goats and sheep. This was complemented with random selection of five animals, either goats or sheep, which were subjected to detailed clinical examination as well as sample collection.

\section{Questionnaire survey}

A semi-structured questionnaire was developed and field tested on a few households keeping goats and sheep in the two districts. The interviews focused on collection of information on flock size, species, age and sex, health and

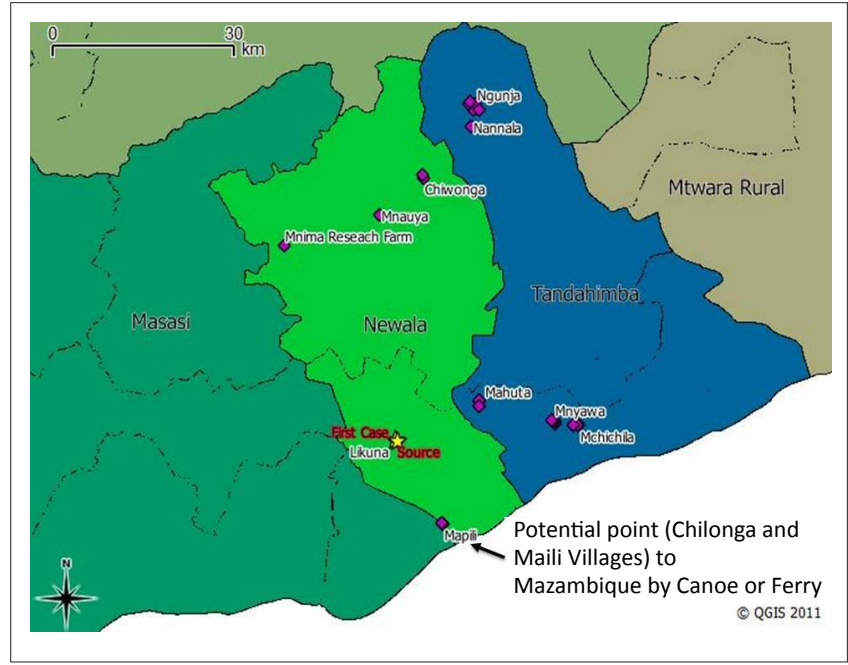

FIGURE 1: Showing sampling points and introduction of Peste des Petits Ruminants in Newala (star).

TABLE 1: The proportions of households, morbidity, mortality, chemotherapy, vaccination and statistics for goats, sheep and people.

\begin{tabular}{llll}
\hline Parameter $\dagger$ & $\begin{array}{l}\text { Newala } \\
(\boldsymbol{n}=\mathbf{3 1})\end{array}$ & $\begin{array}{l}\text { Tandahimba } \\
(\boldsymbol{n}=\mathbf{4 8})\end{array}$ & $\begin{array}{l}\text { Overall } \\
(\boldsymbol{n}=\mathbf{7 9})\end{array}$ \\
\hline Households affected & 19.4 & 81.3 & 57.0 \\
Morbidity & 4.8 & 73.1 & 48.9 \\
Mortality (Crude) & 4.4 & 37.4 & 25.7 \\
Case fatality & 92.9 & 51.2 & 52.6 \\
Households treated (Chemotherapy) & 22.6 & 43.8 & 35.4 \\
Households vaccinated & 0.0 & 0.0 & 0.0 \\
Population statistics $:$ & & & \\
Goat & 105174 & 149945 & 255119 \\
Sheep & 2085 & 2348 & 4433 \\
Human & 183344 & 203837 & 387181 \\
\hline
\end{tabular}

$\dagger$, Parameters are measured in percentage.

$\$$, Statistics are based on figures available in respective District Council Offices in Newala and Tandahimba districts during the study.

vaccination status, and management. Age was approximated and classified as kids or lambs ( $\leq 3$ months), weaners ( $>3$ to $\leq 9$ months) and adults (>9 months). Health status data was collected by recording history of disease outbreak or occurrence, its clinical signs, overall number of sick animals (used to compute morbidity) as well as overall and specific deaths associated with observed clinical cases (used to compute crude and case fatality of PPR). Flock management data included access to animal health and extension services (presence, type and frequency of services), action taken after the outbreak, live animal market visiting frequency and addition of new animals, and suspected source of the infection.

In-depth interviews of key informants were conducted to obtain opinion from local livestock field officers (LFOs) as well as from local government officials in affected villages and wards. The district veterinary officer (DVO) of Newala District and veterinary officers at Mtwara Veterinary Investigation Centre (VIC) were also interviewed to ascertain where and when PPR was first introduced into southern Tanzania and which disease control measures were instituted before the current study. 


\section{Samples collection for Competitive Enzyme Linked Immunosorbent Assay Analysis}

A total of 216 serum samples were collected from goats and sheep in Newala and Tandahimba districts. Initially, blood samples were collected from the jugular vein of each animal using plain Vacutainer tubes. The samples were labelled accordingly to allow identification of each animal and flock sampled and kept in a slanted position overnight to allow serum separation from clotted blood samples. Serum was decanted and aliquoted into $1.5 \mathrm{~mL}$ cryovials before being transported and stored temporarily at the VIC, Mtwara. Finally the serum samples were shipped in a cool box chilled on ice packs to the Laboratory at the VIC, Arusha where serological analysis was carried out.

A monoclonal antibody (MAb) based competitive Enzyme Linked Immunosorbent Assay (cELISA) (Diallo et al. 1995) was used for the detection of antibodies in sera to PPRv using approved competitive ELISA kit as described by Singh et al. (2004a) and Swai et al. (2009). According to the manufacturer, the sensitivity and specificity (for both animal and flock levels) of this cELISA are $99.4 \%$ and $94.5 \%$, respectively. Briefly, the ELISA plates were coated with PPR antigen; the unbound antigen was washed away using buffer then samples were added; Rabbit antimouse-horseradish peroxidase (HRPO) conjugate was added and incubated with constant agitation in each stage. Substrate solution (O-phenylenediamine dihydrochloride containing $\mathrm{H}_{2} \mathrm{O}_{2}$ ) was added allowing for a colour reaction to develop which was halted with the addition of an equal volume of $1 \mathrm{M} \mathrm{H}_{2} \mathrm{SO}_{4}$. The ELISA micro plates were read with an immunoskan reader (Flow laboratories, UK) with an inference filter of $492 \mathrm{~nm}$ and connected to a computer loaded with ELISA Data Information (EDI) software for automated reading and calculation of the percentage inhibition (PI) values.

\section{Samples collection for Reverse Transcriptase Polymerase Chain Reaction}

Samples $(n=28)$ from nasal and eye discharges as well as saliva from oral ulcers were collected from clinically sick sheep and/or goats using sterile swabs which were placed in a viral transport media containing antibiotics and antifungals. The samples were transported on ice to Sokoine University microbiology laboratory for further analysis.

Virological analysis employed Reverse Transcriptase Polymerase Chain Reaction (RT-PCR) to confirm involvement of PPR in suspected cases. Briefly, the test was carried out as follows: The RNA extraction from samples was done using commercial RNA extraction kit $\left(\right.$ Qiagen $\left.^{\circledR}\right)$; the RNA was converted to cDNA using a reverse transcriptase enzyme (Superscript III Platinum One-Step Quantitative, Invitrogen ${ }^{\circledR}$ ). The cDNA was amplified using PPRv specific NP3 and NP4 primers as previously described by CouacyHymann et al. (2002). PCR products were analysed by electrophoresis and visualised in a UV transilluminator.

\section{Statistical data analysis}

Villages, farms and individual animal data were stored in Microsoft Excel 2007 (version 12). Descriptive statistics for the animal and flock level explanatory variables examined in the study were computed using Microsoft Excel. Proportions were calculated for seroprevalence and factors that included animal species, sex and age, location of the flock, health status, management and veterinary services provision. The statistical significance for the proportions was compared using Chi-square test in Epi Info software version 5 (Centre for Disease Control and Prevention). A confidence limit of less than 5\% was used to indicate a significant level. Separate statistical analyses were performed for the data from the two species because previous studies have indicated that virus infection rate and epidemiology may be very different in the two species (Waret-Szkuta et al. 2008). Study village maps were created using Quantum GIS (QGIS 1.4.0 version) Enceladus (Open Source Geospatial Foundation).

\section{Results}

\section{Disease prevalence}

The presence of the PPR infection in southern Tanzania was confirmed by the RT-PCR test whereby $53.6 \%$ of the samples were positive from both sheep and goats.

The overall PPR seroprevalence was 31\% (95\% CI = $24.9 \%-37.6 \%$ ) in the two districts (Figure 2). Tandahimba district recorded higher seroprevalence (55.5\%) compared to the seroprevalence in $5.7 \%$ in Newala district, the difference which was also statistically significant $(p<0.001)$. Mnyawa village recorded highest seroprevalence followed by Nannala, Ngunja, and Mchichira villages of Tandahimba district (Figure 2). Mnima Research Farm had high seroprevalence followed by Chiwonga, Mapili and Mnauya village in that order in Newala district. There was no statistical difference in the seroprevalence recorded in goats $(35.3 \%)$ compared to that in sheep (30.7\%). Similarly, there was no statistical difference in the PPR seroprevalence in female (36.8\%) compared to that recorded in male (29.8\%) animals sampled in this study. Age-wise, $32.1 \%$ of the adults and $22.7 \%$ of the kids or lambs were seropositive, however, there was no statistical difference.

The PPR prevalence based on reported cases observed by interviewees is shown in Table 1 . Overall, $57 \%$ of 79 households visited had experienced suspected PPR cases in their flocks. Again, a significantly higher proportion of households in Tandahimba $(81.3 \%)$ had PPR cases than those in Newala district $(19.4 \% ; p<0.001)$. A similar trend was also observed with respect to morbidity of PPR when Tandanimba recorded higher morbidity $(73.1 \%)$ compared to that in Newala district $(4.8 \% ; p<0.001)$. Clinically, a significantly higher proportion of goats (90.9\%) were reported to be sick compared to only $9.1 \%$ sheep which were sick $(P<0.001)$. A similar trend in mortality was recorded when the proportion of goats and sheep which died was $93.4 \%$ and $6.6 \%$, respectively $(P=0.059)$. A good number of 


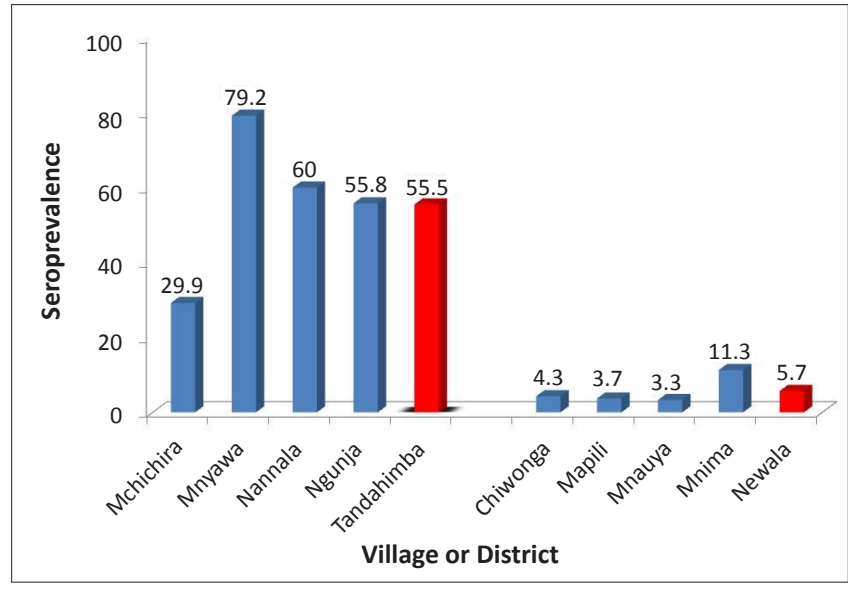

FIGURE 2: Seroprevalence by villages or district.

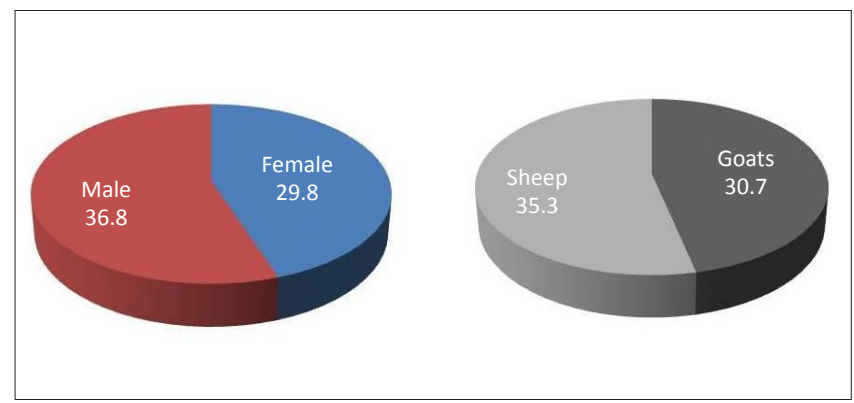

FIGURE 3: Proportions (\%) for seroprevalence by sex (left) and species (right).

small ruminant owners also reported to treat their animals using antibiotics as shown in Table 1.

\section{Management practices}

It was observed that goats and sheep in the two districts are managed in two different ways. The first group keeps animals in small group in small houses on a raised floor at night and graze in a community land during day time. The second group manage animals collectively by keeping them together in groups in relatively large animal houses on ground floor and utilise communal grazing. Goats and sheep are kept for meat and for sale in order to generate income for the household.

There were more male respondents interviewed $(90.0 \%)$ in comparison to female respondents (10.0\%; Table 2). Only a few respondents in Newala district tethered their animals at night (10.1\%) and most (94.9\%) farmers kept their animals in a small raised house at night. All (100\%) of the respondents utilised communal grazing areas (Table 2).

\section{Introduction of Peste des Petits Ruminants in southern Tanzania}

The in-depth interview revealed that PPR was introduced in the southern Tanzania for the first time in goats and sheep in February 2009. The current study managed to trace a village where sick animals started which was Likuna village of Newala district. It was observed that PPR introduction was through newly purchased goats from the Pugu livestock market located about $679 \mathrm{~km}$ in the outskirts of Dar es Salaam city. These animals were brought in about one week prior to the disease outbreak. Other villages in close proximity of this village that reported outbreak of PPR in the same month were Kikuyu, Makote, Namiyonga, Lidumbe and Mkunya. It was confirmed that these five villages had also received some of these goats from Pugu Livestock Market. The disease spread to neighbouring Tandahimba District through buying sick and cheap animals from Newala district with the intention of selling them at Tandahimba live animal markets and butcheries.

\section{Observed clinical signs}

Different clinical signs were reported by livestock keepers in suspected PPR cases. The signs included diarrhoea, lacrimation, nasal discharges, respiratory distress, oral ulcers and skin nodules (Figure 4).

\section{Economic losses}

The economic loss due to mortality in two districts was $25.7 \%$ and case fatality rate was $52.6 \%$ (Table 1 ). Case fatality rate was higher in Newala district $(92.9 \%)$ compared to $(51.2 \%)$ in Tandahimba district $(P<0.000)$.

TABLE 2: Proportions of respondents' sex, animal management, awareness of the disease, source and spreading of the infection and veterinary extension services. Parameter $\quad$ Newala Tandahimba Overall

\begin{tabular}{llll} 
& $(\boldsymbol{n}=\mathbf{3 1})$ & $(\boldsymbol{n}=\mathbf{4 8})$ & $(\boldsymbol{n}=\mathbf{7 9})$ \\
\hline Household head sex & & & \\
Male & 32.9 & 57.0 & 89.9 \\
Female & 5.1 & 5.1 & 10.1 \\
Animal management & & & \\
Animal tethering & 10.1 & 0.0 & 10.1 \\
Boma & 36.7 & 58.2 & 94.9 \\
Communal grazing & 39.2 & 60.8 & 100 \\
Livestock keepers' awareness & & & \\
Outbreak awareness & 3.8 & 60.8 & 64.6 \\
Seen affected animals & 11.4 & 57.0 & 68.4 \\
Own animals affected & 7.6 & 49.4 & 57.0 \\
Knowledge of what disease it was & 1.4 & 1.4 & 2.9 \\
Seen similar disease in past & 1.3 & 5.1 & 6.5 \\
Extension worker present & 17.8 & 41.1 & 58.9 \\
Regular animal inspection & 17.6 & 35.3 & 52.9 \\
Frequency of inspection & & & \\
At least once a month & 15.4 & 24.6 & 40.0 \\
Once in several months & 3.1 & 10.8 & 13.8 \\
No visit at all & 24.6 & 9.2 & 33.8 \\
Visit when called & 0.0 & 12.3 & 12.3 \\
Source of infection and spread & & & \\
Unknown cause & 0.0 & 36.7 & 36.7 \\
Change of weather & 0.0 & 20.0 & 20.0 \\
Communal grazing area & 10.0 & 33.3 & 43.3 \\
\hline
\end{tabular}

$\dagger$, Parameters are measured in percentage.

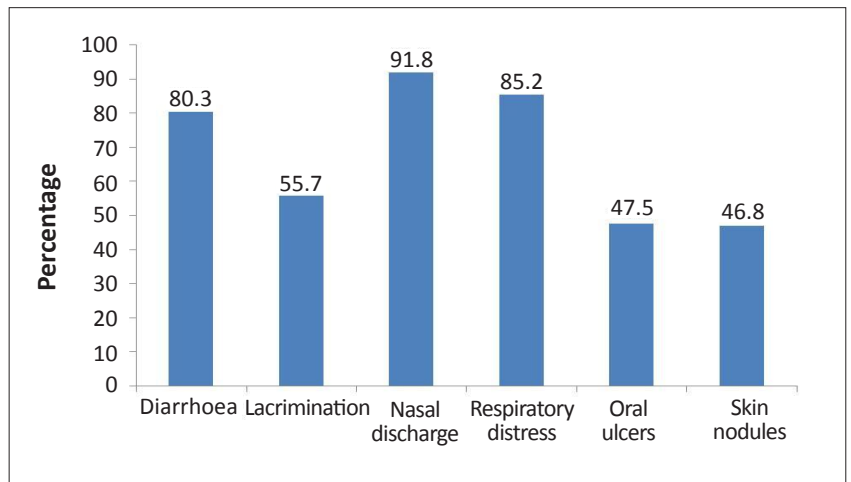

FIGURE 4: Clinical signs presented by Peste des Petits Ruminants disease. 


\section{Disease awareness and vaccination}

Over $60.8 \%$ of respondents in Tandahimba were aware of the disease outbreak and $49.4 \%$ had their own animals affected (Table 2). Very few livestock keepers (2.9\%) knew what disease it was and only $(6.5 \%)$ though that they had seen it in the past. During the outbreak, animal owners (35.4\%) from the two districts treated their animals using chemotherapy whereas $22.6 \%$ were from Newala and $43.8 \%$ were from Tandahimba (Table 1). More than half $(58.9 \%)$ had veterinary extension workers in their villages but half $(52.9 \%)$ of the farmers reported regular health inspection for their animals, although the frequency of inspection varied (Table 2). All (100\%) respondents had not vaccinated their animals (Table 1 ). The source of the infection and spread was suspected by farmers to be communal grazing and change of weather conditions, with more animals being affected during the rainy season.

\section{Discussion}

This study has confirmed the aetiology of the disease outbreak that occurred in the districts of Tandahimba and Newala in southern Tanzania to be PPR in March 2011. It has also identified the village where the first introduction and consequently, the source of PPR spread in southern Tanzania happened. Although it took only one year from first official confirmation of the disease in northern Tanzania to introduction in southern Tanzania, it has taken about two years to confirm this disease through efforts of the current study. This is consistent with the findings by Karimuribo et al. (2011) of delayed confirmation following introduction of PPR in the country. These findings point to the importance of having efficient disease surveillance and diagnostic capacity especially for emerging and re-emerging fatal diseases affecting animal populations.

In this study it was found out that the source of the disease was through the introduction of new animals purchased from live animal market. Similar sources of the disease have been implicated before (Singh et al. 2004a; Muhammad et al. 2009).

The proportions of sero-converted animals examined in the area under study was low (31.0\%) compared to the reports from northern Tanzania (45.5\%) (Swai et al. 2009) but at the flock level the prevalence was high (48.9\%). Ozkul et al. (2002) in Turkey found comparable findings whereby the overall prevalence was low based on antibody test and higher based on clinical signs. Low PPR seroprevalence have also been reported in Tunisia (Ayari-Fakhfakh et al. 2010).

Although the seroprevalence was low in this study it has been shown elsewhere that seroprevalence can be as high as $45.5 \%$, $78 \%$ and $92.5 \%$, as reported in Cameroon, Nigeria and Sudan respectively (Ekue et al. 1992; Obidike et al. 2006; Osman et al. 2008) using neutralisation and haemagglutination tests. When the competitive ELISA method was used the seroprevalence was reported to be $51 \%$ and $50 \%$ (Khan et al. 2008; Misbah et al. 2009) in Pakistan. The inconsistency in the seroprevalence of antibodies to PPRv in different areas is attributed to variations in a number of factors including the management system, levels of immunity, diagnostic test, sampling procedures used and technical know-how of the researchers (Singh et al. 2004b; Waret-Szkuta et al. 2008). In this study, goats were reported to show an acute form of the disease whilst sheep showed a sub-acute or chronic form; this finding is supported by other studies (Obi, Rowe \& Taylor 1984; Swai et al. 2009).

Although, the differences observed between males and females was not significant Swai et al. (2009) observed sex differences in sheep whereby males were more affected compared to females. With respect to age category, the highest prevalence of PPR was observed in adults compared to other age category. This result is in agreement with other finds observed in Ethiopia and India (Singh et al. 2004a; Waret-Szkuta et al. 2008) where they reported high prevalence in adults. Association with seasonal (weather) changes observed by farmers has been reported elsewhere (Singh et al. 2004a; Muhammad et al. 2009).

Even though the PPR was introduced in Newala, it was more prevalent in Tandahimba district. The reasons are thought to be first selling of sick animals from Newala to Tandahimba animal markets and butcheries and secondly the livestock keepers in Tandahimba district managed their animals by utilising more $(60.8 \%)$ communal grazing compared to Newala district (39.2\%) (Table 2).

This study revealed that more than half of the farmers have little or no access to veterinary services. Lack of appropriate veterinary services and inadequate infrastructure especially in the local live animal markets in the country, may facilitate disease transmission. Extra attention from the government to upgrade the handling and penning facilities of these market places could result in reduced level of disease transmission. Efforts should be make to increase livestock and public awareness with respect to this new disease in the area. The current ongoing government efforts to perform PPR vaccination of goats and sheep in unaffected villages should be encouraged.

\section{Conclusion}

This study has confirmed, for the first time, the presence of the PPR in southern Tanzania. In addition, the study has identified the source of introduction of PPR to be newly purchased animals from Pugu Livestock Market. Given that no vaccinations had been carried out against PPR, our result confirms natural transmission of PPR virus under field conditions in the southern Tanzania. The spread of this disease to southern Tanzania poses a high risk of the disease spread to southern countries (SADC countries including Mozambique, Zambia and Malawi) with naïve goat and sheep populations. Further studies on virus isolation, disease status in wildlife and temporal trends events are required to define the epidemiology of PPR in large area of the southern Tanzania. National, regional and international collaborative efforts are required to contain and control the disease. 


\section{Aknowledgement}

We would like to thank the project of RUFORUM (RU 2009 GRG 17TADs) for supporting this work. We also extend our appreciations to the staff at Mtwara Veterinary Investigation Centre, field officers and farmers for their invaluable contributions in terms of their time and cooperation. In addition, we value VIC Arusha SUA technician for laboratory technical assistance.

\section{References}

Abu Elzein, E.M.E., Housawi, F.M.T., Bashareek, Y., Gameel, A.A., Al- Afaleq, A.I. \& Anderson, E.C., 2004, 'Severe PPR infection in Gazelles kept under semi-free range conditions in Saudi Arabia', Journal of Veterinary Microbiology B 51, 68-71. http:// dx.doi.org/10.1111/j.1439-0450.2004.00731.x, PMid:15030603

Ashley, C.B., Satya, P., Carrie, B., Chris, O., Olivier, K. \& Genevieve, L., 2010, 'Global distribution of peste des petits ruminants virus and prospects for improved diagnosis and control', Journal of General Virology 91, 2885-2897. http://dx.doi. org/10.1099/vir.0.025841-0, PMid:20844089

Awa, D.N., Njoya, A. \& Ngo Tama, A.C., 2000, 'Economics of prophylaxis against peste des petits ruminants and gastrointestinal helminthosis in smal ruminants in north Cameroon', Tropical Animal Health and Production 32, 391-403. http://dx.doi.org/10.1023/A:1005233703331, PMid:11147279

Ayari-Fakhfakh, E., Ghram, A., Bouattour, A., Larbi, I., Gribaa-Dridi, L., Kwiatek, O. et al., 2010, 'First serological investigation of peste-des-petits-ruminants and Rift Valley fever in Tunisia', Veterinary Journal (In Press).

Balamurugan, V., Sen, A., Venkatesan, G., Yadav, V., Bhanuprakash, V. \& Singh, R.K., 2010, Isolation and identification of virulent peste des petits ruminants viruses from PPR outbreaks in India', Tropical Animal Health and Production 42, 10431046. http://dx.doi.org/10.1007/s11250-010-9527-0, PMid:20204510

Chauhan, H.C., Chandel, B.S, Kher, H.N., Dadawala, A.I. \& Agrawal, S.M., 2009, 'Peste des petits ruminants virus infection in animals', Veterinary World 2, 150-155.

Couacy-Hymann, E., Roger, F., Hurard, C., Guillou, J.P., Libeau, G. \& Diallo, A., 2002, 'Rapid and sensitive detection of peste des petits ruminants virus by a polymerase chain reaction assay', Journal of Virology Methods 100, 17-25. http://dx.doi. org/10.1016/S0166-0934(01)00386-X

Diallo, A., Libeau, G., Couacy-Hymann, E. \& Barbron, M., 1995, 'Recent developments in the diagnosis of rinderpest and peste des petits ruminants', Veterinary Microbiology 44, 307- 317. http://dx doi.org/10.1016/0378-1135(95)00025-6

Ekue, N.F., Tanya, V.N., Ndi, C. \& Saliki, J.T., 1992, 'A serological survey of antibodies against peste des petits ruminants (PPR) in small ruminants in Cameroon', Bulletin of Animal Health and Production in Africa 40, 49-53.

FAO (2010), 'Deadly animal virus Peste des Petits Ruminants threatens to spread to souther Africa', Goal Geology, viewed 16 January 2011, from -animal-virus-pestedes-petits-ruminants-threatens-to-spread-to-southern-africa/8302/

Karimuribo, E.D., Loomu, P.M., Mellau, L.S.B. \& Swai, E.S., 2011, 'Retrospective study on sero-epidemiology of peste des petits ruminants before its official confirmation in northern Tanzania in 2008', Research Opinions in Animal and Veterinary Sciences 1, 184-187.
Khalafalla, A.I., Saeed, I.K., Ali, Y.H., Abdurrahman, M.B., Kwiatek, O., Libeau, G. et al., 2010, 'An outbreak of peste des petits ruminants (PPR) in camels in the Sudan', Acta Tropica 116, 161-165. http://dx.doi.org/10.1016/j.actatropica.2010.08.002, Acta Tropica 116

Khan, H.A., Siddique, M., Sajjad-ur-Rahman, Abubakar, M. \& Ashraf, M., 2008, 'The detection of antibody against peste des petits ruminants virus in sheep, goats, cattle and buffalo', Tropical Animal Health and Production 40, 521-527. http://dx.doi.org/10.1007/s11250-008-9129-2, PMid:18716909

Kivaria, F.M., Kwiatek, O., Kapaga, A.M., Geneviève, L., Mpelumbe-Ngeleja, C.A.R. \& Tinuga, D.K., 2009, 'Serological and virological investigations on an emerging peste des petits ruminants virus infection in goats and sheep in Tanzania', pape presented at the 27th Tanzania Veterinary Association Scientific Conference, Arusha, Tanzania, 04-06 December.

Misbah, A., Muhammad, A., Rehana, A., Shamim, S. \& Qurban, A., 2009, 'Prevalence of peste des petits ruminants virus (PPRV) in Mardan, Hangu and Kohat District
of Pakistan; Comparative analysis of PPRV suspected serum samples using of Pakistan; Comparative analysis of PPRV suspected serum samples using
competitive ELISA (cELISA) and agar gel immunodiffusion (AGID)', Veterinary Competitive ELISA

Muhammad, A., Syed, M.J., Muhammad, J.A., Manzoor, H. \& Qurban, A., 2009, 'Peste des petits ruminants virus (PPRV) infection: Its association with species, seasonal variations and geography', Tropical Animal Health and Production 41, 1197variations and geography', Tropical Animal Health and Production
1202. http://dx.doi.org/10.1007/s11250-008-9300-9, PMid:19130284

Nussieba, A.O., Ali, A.S., Mahasin, E.A.R. \& Fadol, M.A., 2009, 'Antibody seroprevalences against peste des petits ruminants (PPR) virus in sheep and goats in Sudan', Tropical Animal Health and Production 41, 1449-1453. http://dx.doi.org/10.1007/s11250009-9333-8, PMid:19798772

Obi, T.U., Rowe, L.W. \& Taylor, W.P., 1984, 'Serological studies with Peste des petits ruminants and Rinderpest viruses in Nigeria', Tropical Animal Health and Production 16, 115-118. http://dx.doi.org/10.1007/BF02239855, PMid:6485096

Obidike, R.I., Ezeibe, M.C.O., Omeje, J.T.N. \& Ugwuomarima, K.G., 2006, 'Incidence of peste de petits ruminants in farm and market goats in Nsukka, Enugu State Nigeria', Bulletin of Animal Health and Production in Africa 54, 148-150. http:// dx.doi.org/10.4314/bahpa.v54i2.32742

Osman, N.A., Mahasin, E., Rahman, A., Ali, A.S. \& Fadol, M.A., 2008, 'Rapid detection of peste des petits ruminants (PPR) virus antigen in Sudan by agar gel precipitation (AGPT) and haemagglutination (HA) Testes', Tropical Animal Health and Production 40, 363-368. http://dx.doi.org/10.1007/s11250-007-9106-1

Ozkul, A., Akca, Y., Alkan, F., Barrett, T., Karaoglu, T., Dagalp, S.B. et al., 2002 'Prevalence, distribution, and host range of peste des petits ruminants virus in Turkey', Emerging Infectious Diseases 8, 708-712. PMid:12095439

Singh, R.P., Saravanan, P., Sreenivasa, B.P., Singh, R.K. \& Singh, B., 2004a, 'Prevalence and distribution of peste des petits ruminants virus infection in small ruminants in India', Revue Scientifique et Technique (OIE) 23, 807-819. PMid:15861876

Singh, R.P., Sreenivasa, B.P., Dhar, P., Shah, L.C. \& Bandyopadhyay, S.K., 2004b, 'Development of monoclonal antibody based competitive ELISA for detection and titration of antibodies to peste des petits ruminants (PPR) virus', Veterinary Microbiology 98, 3-15. http://dx.doi.org/10.1016/j.vetmic.2003.07.007, PMid:14738776

Swai, E.S., Kapaga, A., Kivaria, F., Tinuga, D., Joshua, G. \& Sanka, P., 2009, 'Prevalence and distribution of peste des petits ruminants virus antibodies in various districts of Tanzania', Veterinary Research Communications 33, 927-936. http://dx.doi. org/10.1007/s11259-009-9311-7, PMid:19705291

Wang, Z., Bao, J., Wu, X., Liu, Y., Li, L., Liu, C. et al., 2009, 'Peste des petits ruminants virus in Tibet, China', Emerging Infectious Diseases 15, 299-301. http://dx.doi. org/10.3201/eid1502.080817, PMid:19193278

Waret-Szkuta, A., Roger, F., Chavernac, D., Yigezu, L., Libeau, G., Pfeiffer, D.U. et al., 2008, 'Peste des petits ruminants (PPR) in Ethiopia: analysis of a national serological survey', BMC Veterinary Research 4, viewed 16 January 2011, from http://www.biomedcentral.com/1746-6148/4/34 